EGU21-828

https://doi.org/10.5194/egusphere-egu21-828

EGU General Assembly 2021

(c) Author(s) 2022. This work is distributed under

the Creative Commons Attribution 4.0 License.

\title{
Dominant role of North tropical Atlantic 2017 warm event on equatorial variability
}

\author{
Ana Trindade ${ }^{1,2}$, Marta Martín-Rey ${ }^{2}$, Marcos Portabella ${ }^{2}$, Eleftheria Exarchou ${ }^{3}$, Pablo Ortega ${ }^{3}$, and \\ Iñigo Gómara ${ }^{4}$ \\ ${ }^{1}$ Universitat Politecnica de Catalunya, Barcelona, Spain (atrindade@icm.csic.es) \\ ${ }^{2}$ Instituto de Ciencias del Mar (ICM), CSIC, Barcelona, Spain \\ ${ }^{3}$ Barcelona Supercomputing Center (BSC), Barcelona, Spain \\ ${ }^{4}$ Universidad Complutense de Madrid (UCM), Madrid, Spain
}

Multiple lines of new evidence suggest that the Atlantic Ocean plays an active role in the modulation of global climate. Special attention deserves tropical Atlantic extreme events that have increased from 2000s causing severe winter conditions in the Euro-Atlantic region and originating the most devastating hurricane seasons on record (Foltz and McPhaden 2006; Bucham et al. 2014; Lim et al. 2018; Klotzbach et al. 2018). In 2017, the north Tropical Atlantic (NTA) experienced a profound warming, resembling the Atlantic Meridional Mode (AMM) pattern, that originated a destructive hurricane season with catastrophic social and economic damages (Klotzbach et al. 2018). Previous studies focused their attention on the description of the precursors and predictability of the 2017 hurricane season. Nevertheless, the impact of the 2017 NTA warming on equatorial SST variability has not been explored so far. Recent findings put forward the key role of the AMM-associated cross-equatorial wind to trigger oceanic waves that impact on equatorial SSTs (Martín-Rey and Lazar 2019; Foltz and McPhaden 2010).

Thus, in the present study, we investigate the connection between NTA and equatorial variability during 2017, as well as the importance of an accurate ocean forcing to correctly simulate this event. For such purpose, a suite of three initialized climate predictions, performed with the climate model EC-Earth (version3.3), are analyzed. Two sets of predictions apply a wind stress correction over the Tropical Atlantic (35S-35N) using two distinct wind stress products: ERA-Interim (ERAl) reanalysis and a new ERAl-corrected (ERA*) wind product, which are compared to a control prediction with model-generated wind stress (MOD). ERA* has been developed based on means of a geolocated scatterometer-based correction applied to the ERA-interim reanalysis (Trindade et al. 2019). The high-quality of the scatterometer stress-equivalent winds (Portabella and Stoffelen 2009; De Kloe et al., 2017) allows ERA* to contain some of the physical processes missing or misrepresented (i.e., small-scale ocean processes, such as wind-current interaction) in ERAI.

Using more realistic surface wind stress (ERAI or ERA* with respect to MOD) considerably improves the simulation of eastern NTA and equatorial warming. The novel wind stress product $\left(\right.$ ERA* $^{*}$ respect its precursor ERAI, better represents the off-shore warm SSTs in the NTA and along 
eastern equatorial Atlantic and south African coast. It is worth mentioning that oceanic wave activity proves highly sensitivity when forced by realistic ERAI and ERA* wind stress products. In the wind-corrected experiments, an anomalous wind stress curl north of the equator during March-April excites a downwelling Rossby wave that propagates to the west and is boundary reflected in June-July, becoming an equatorial downwelling Kelvin wave (dKW). This dKW displaces eastward favouring the development of an equatorial warming in late-summer and fall. ERA* does not show significant changes in the RW generation, but in the amplitude of equatorial KW during summer season.

Our results highlight the importance of using improved wind stress products to achieve a correct simulation of ocean wave activity and in turn equatorial Atlantic SST variability. This information is of great value for improving current seasonal forecast systems. 